\title{
Recent advances in the understanding of acute kidney injury Florian Tögel ${ }^{1}$ and Christof Westenfelder ${ }^{2,3 *}$
}

\author{
Addresses: ${ }^{1}$ Division of Renal (Kidney) Medicine, Brigham and Women's Hospital, 45 Francis Street, Boston, MA 02115, USA; ${ }^{2}$ Department of \\ Medicine, Division of Nephrology, Department of Physiology, University of Utah, Salt Lake City, UT, USA; ${ }^{3}$ George E. Wahlen VA HSC \\ Medical Center, 500 Foothill Boulevard, Salt Lake City, UT 84148, USA \\ *Corresponding author: Christof Westenfelder (christof.westenfelder@hsc.utah.edu) \\ Fl000Prime Reports 2014, 6:83 (doi:10.12703/P6-83) \\ All Fl000Prime Reports articles are distributed under the terms of the Creative Commons Attribution-Non Commercial License \\ (http://creativecommons.org/licenses/by-nc/3.0/legalcode), which permits non-commercial use, distribution, and reproduction in any medium, \\ provided the original work is properly cited. \\ The electronic version of this article is the complete one and can be found at: http://fl000.com/prime/reports/m/6/83
}

\begin{abstract}
Acute kidney injury (AKI) is a common clinical entity associated with high morbidity and mortality and clinical costs. The pathophysiology is multifaceted and involves inflammation, tubular injury, and vascular damage. Recently identified components include necroptosis, a special form of cell death, and autophagy. Most of the pathophysiological knowledge is obtained from animal models but these do not directly reflect the reality of the clinical situation. Tubular cells have a remarkable capacity to regenerate, and the role of stem/progenitor cells is discussed. Acute kidney injury is frequently associated with chronic kidney disease, and the implications are widespread.
\end{abstract}

\section{Introduction}

AKI remains an immense clinical problem that is associated with high morbidity and mortality rates and affects a growing number of hospitalized patients. There is not only significant physical injury to millions of individual patients but also a large economic impact to society as evidenced by increased length of hospital stay and higher costs [1]. To put the economic burden into perspective, AKI is estimated to cost the National Health Service (NHS) in the UK (excluding costs in the community) between $£ 434$ million and $£ 620$ million per year (NHS Kidney Care estimate) because of prolonged hospitalizations and short- and long-term morbidities [2]. In 2005, Chertow and colleagues [3] estimated that the annual costs for hospital-acquired AKI were approximately $\$ 10$ billion in the US.

AKI is the descriptive term for the clinical condition that occurs when the renal excretory function is critically and acutely decreased to a point at which the body accumulates "uremic" waste products and becomes unable to maintain electrolyte, acid-base, and water balance. In clinical terms, AKI is measured as an increase in serum creatinine, a biomarker that is universally used but that has considerable diagnostic limitations given its variability, dependence on body muscle mass, and delay in accumulation.

AKI is a clinical entity and has various etiologies that include interstitial nephritis, rapidly progressive glomerulonephritis, obstructive nephropathy, and renovascular complications but is frequently the consequence of ischemic and toxic insults and also occurs commonly in the setting of sepsis. In sepsis, the circulation is hyperdynamic and blood flow is altered, though not necessarily in the ischemic range, while the glomerular filtration rate drops rapidly [4]. The pathophysiology of sepsis-associated AKI is very complex and involves an intricate interplay of inflammation, oxidative stress, microvascular dysfunction, and further amplification of injury by the secretion of chemokines and cytokines by tubular cells [5]. In laboratory science, the pathophysiology and therapy of AKI are most commonly investigated in animals with ischemia/reperfusion injury induced by clamping of both renal pedicles. Other less commonly used models include toxic injury models (for example, cisplatinum and folic acid) and a sepsis model using cecal ligation and puncture [6]. Accordingly, most knowledge regarding the pathophysiology of AKI has 
been derived from preclinical studies in rats and mice with ischemia/reperfusion-induced AKI.

One of the major obstacles that has hampered therapeutic progress in AKI is the fact that effective interventions in animals were obtained in otherwise healthy animals but that most patients who develop AKI present with significant co-morbidities such as older age, underlying chronic kidney disease (CKD), and diabetes-conditions that are not considered in animals. In addition, AKI in most patients occurs as a syndrome of multiple coexisting etiologies, including ischemia, toxicity, and functional impairment, whereas animal models used for the study of its pathophysiology and therapy are generally monocausal and simplistic and often exhibit species-specific characteristics.

\section{Components of the pathophysiological process and renoprotection}

AKI is the clinical endpoint of a number of processes resulting in a decrease of the glomerular filtration rate, a measure of global renal function. Important components of the injury process include apoptosis, necrosis, reactive oxygen species, and micro-vessel damage causing local ischemia, endothelial dysfunction, leaks, and inflammation (see figure 1). Several stages of AKI have been delineated: initiation, extension, maintenance, and recovery phases [7]; however, in the clinical situation, these are not clear-cut and often appear overlapping. Apoptosis and, to a lesser extent, necrosis of renal cells are the main forms of cell death caused by injury. However, recently identified new pathways of programmed cell death summarized under the term "necroptosis" also contribute to a variable degree to tissue damage. Necroptosis has been recognized as a regulated process under ischemic conditions with at least three pathways involved: receptor-interacting protein kinase 3 (RIP3)-dependent necroptosis, cyclophilin D-dependent pathways, and a pathway involving the poly (ADP-ribose) polymerase-calpain axis [8]. Recently developed approaches for translational profiling, based on transgenic animal models, facilitate a detailed approach to the identification of injury-induced changes in gene expression patterns [9]. These data show that a wide network of genes is activated at 24 hours after injury and is characterized by strong expression of anti-apoptotic and "anti-necrotic" pathways as well as the upregulation of genes involved in cell movement and formation of cell junctions. These findings confirm the clinical observation of the robust regenerative potential of the tubular epithelium. In addition, these data show that components of the normal tubular physiology are rapidly downregulated post-injury.

Clinically, the kidney shows a remarkable capacity to recover from injury. It is not unusual that the kidney fully recovers its function, as measured by serum creatinine levels, even in cases in which patients become dialysis dependent for weeks. Although clinical recovery appears complete, as measured by serum creatinine, there is structural and subclinical damage, which is undetectable by current clinical methods but which enhances susceptibility to injury as well as development of progressive CKD.

Tubular cells are capable of activating a number of cytoprotective mechanisms, which include the expression of heat shock proteins and cell cycle regulatory proteins such as p21 [10]. Surviving tubular cells facilitate recovery and repair through proliferation and migration after injury, resulting in the repopulation of denuded nephron segments [11]. Autophagy, a process of self-clearing of broken-down subcellular components that are fed into the lysosomal degradation pathway, is induced after injury and has been described as a renoprotective mechanism used by tubular cells [12].

Protection of the kidney can be induced experimentally through ischemic preconditioning whereby a sublethal ischemic insult prevents greater damage from future ischemic episodes through a number of proposed and observed mechanisms, including nitric oxide induction, cellular kinases, heat shock proteins, and neurogenic pathways, all of which augment cellular resistance to injury. This phenomenon was described about a century ago in the kidney in the setting of uranium-induced injury [13]. This experimental finding has been tested in clinical trials with some promising but preliminary results [14].

\section{Animal models versus clinical acute kidney injury} The histopathology of AKI in humans is a largely uncharted territory because of the rarity of biopsies performed in the acute phase of injury. The commonly used term "acute tubular necrosis" is a misnomer given that necrosis is very localized to some small focal areas and that the cell death processes involved include apoptosis and desquamation of viable cells in addition to small focal necrotic areas [15]. Human AKI differs considerably from the ischemia/reperfusion mouse model, in which large areas of kidney cortex are essentially no longer perfused, resulting in cortical necrosis. In the human situation, blood flow never fully ceases and damage occurs mainly from focal mismatches of oxygen delivery by impaired microcirculation and increased demand due to cellular stress. Questions regarding the extent of damage as well as the cell types affected by damage (that is, distal versus proximal tubular cell types) have remained controversial [16]. Again, this debate is based primarily on data of rodent models since human AKI and particularly the deeper sections of the kidney (including the medulla) are rarely biopsied in the acute setting. The few data available 
Figure I. Pathophysiological components of acute kidney injury

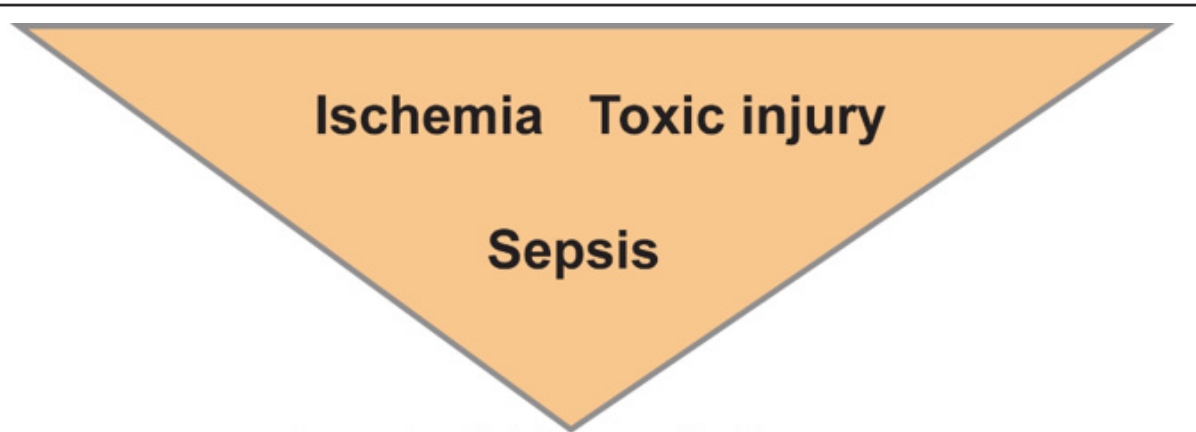

\section{Acute kidney injury}

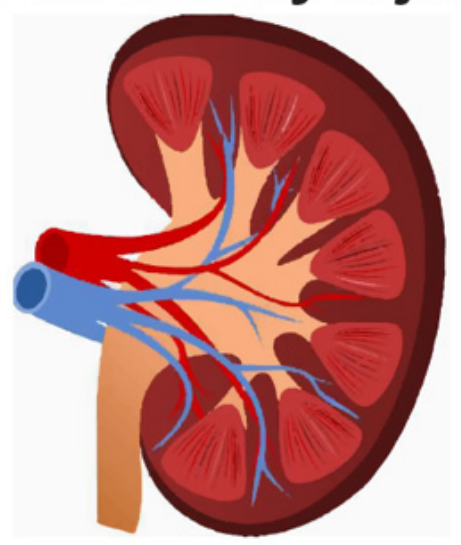

\section{Inflammation}

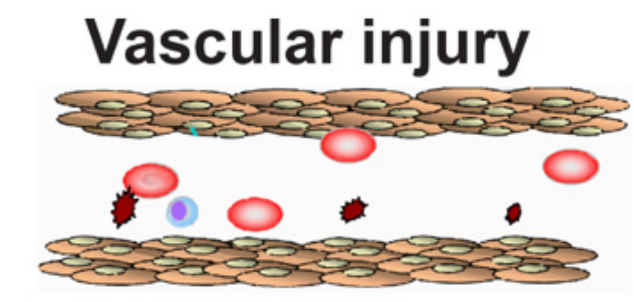

Tubular injury

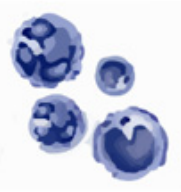

Direct tubular injury through NK cells, neutrophils and macrophages

Cytokine/chemokine release
Endothelial dysfunction

Microvascular obstruction

Vasoconstriction

Coagulopathy

Vascular leakage/edema

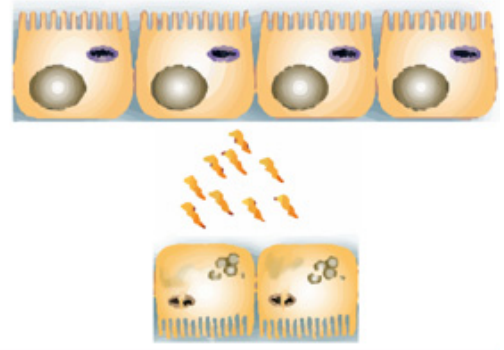

Cell death:

- necrosis

- apoptosis

- necroptosis

Brush border loss

Loss of cell polarity

Dedifferentiation

Tubular obstruction/casts

Acute kidney injury is most commonly caused by ischemic or toxic injury and occurs in the setting of sepsis. Components of the pathophysiology include inflammatory responses as well as tubular and vascular damage and its consequences. Abbreviations: NK, natural killer. 
in the human situation paint a very different picture compared with animal models. A large study by Liaño and Pascual [17] from 1996 reported 748 cases of AKI, with "acute tubular necrosis" (45\%) being the most frequent cause, followed by prerenal failure (21\%), acute-onset chronic renal failure $(12.7 \%)$, and obstructive acute renal failure $(10 \%)$. However, the total number of renal biopsies performed in this study was low (6.1\%) [17]. A study from 2008 analyzing the Spanish Registry of Glomerulonephritis found that $16.1 \%$ of all biopsies $(n=2,281)$ were diagnosed with acute renal failure and diagnoses were quite different, with vasculitis (23.3\%), acute tubulointerstitial nephritis $(11.3 \%)$, and crescentic glomerulonephritis types 1 and $2(10.1 \%)$ as leading diagnoses among AKI cases [18]. Although the study was obviously limited by a strong selection bias given that most patients with AKI were never biopsied in this glomerulonephritis registry, the data underscore the existence of a large knowledge gap regarding the actual histopathology of human AKI.

Although human data are sparse, the inflammatory component, as evidenced by infiltrating leukocytes, is rather small and most leukocytes are found within the vasa recta. In contrast, in the mouse model of AKI, inflammation is a prominent part of the injury cascade. Mouse ischemic AKI is characterized by extensive infiltrates of inflammatory cells, which contribute to injury propagation by secreting pro-inflammatory cytokines and factors. Different leukocyte populations, including $\mathrm{T}$ and $\mathrm{B}$ cells, natural killer cells, T-regulatory cells, dendritic cells, and macrophages, have all been described to play various roles in the pathophysiology of and recovery from AKI [19]. Most of the studies investigating leukocyte populations have been conducted in mouse models, and this is largely because of the ready availability of immunodeficient mice as well as bone marrow transplantation models. In contrast to the mouse model, the rat model exhibits prominent apoptosis of tubular cells as the major pathophysiological component and leukocytes play a minor role. A recent study by Sutton and colleagues [20] demonstrates the dilemma between models impressively: in mice, p53 inhibition is detrimental by enhancing the inflammatory component; this is in contrast to the rat model, in which p53 inhibition is protective, mainly by reducing the amount of tubular cell apoptosis [21].

\section{Regeneration of tubular cells}

Tubular regeneration has been described as originating from surviving tubular cells that are depolarized and de-differentiated and that proliferate, migrate, and re-differentiate to repopulate denuded tubular segments [22]. Studies have shown that tubular cells of the S3 segment exhibit a particularly robust proliferative response in response to acute injury. These cells promptly re-enter the cell cycle and thereby contribute to the repair of injured nephron segments [23]. Observations regarding the spontaneous contribution of stem cells from extra-renal sources, including bone marrow-derived stem cells, to kidney regeneration have been published $[24,25]$. However, careful lineage-tracing studies have shown that their contribution is either absent or at the most minimal, thereby suggesting that intrinsic renal cells carry out the repair of the injured kidney [26-28]. Based on these observations, further debate regarding the mechanism of kidney repair following AKI is focused on the existence and role of kidney-specific stem/progenitor cells versus regeneration carried out mainly by surviving tubular cells that do not express stem cell markers.

A leading hypothesis posits that all differentiated proximal tubule epithelia have the capacity to proliferate during repair by a mechanism of reversible dedifferentiation and self-duplication [22]. On the other hand, it has been postulated that stem/progenitor cells of intratubular origin are the main executioners of tubular regeneration [29]. The terms "stem" and "progenitor" cells are frequently used interchangeably, but, in general, the term "progenitor cells" refers to a more restricted population of cells that might not be able to differentiate into a whole array of cells.

Carefully designed studies using the Six2-Cre driver, a genetic tool for the irreversible marking of a population of cells defined by a specific marker, were carried out to lineage-trace and thus assess the contribution of intrinsic tubular cells to nephron repair. The latter was confirmed, and no evidence for a role of extrarenal cells in this process was detected [26]. This study, however, was unable to exclude the existence of intratubular stem or progenitor cells. More recent publications, using sophisticated lineagetracing methods, have provided evidence that all tubular cells are equally able to contribute to regeneration after injury, thereby providing indirect evidence against the existence of a distinct progenitor cell population $[11,30]$.

\section{Chronic kidney disease resulting from acute kidney injury}

For a long time, the belief was that recovery from AKI is complete and leads to a restitutio ad integrum. Indeed, renal function, as measured by serum creatinine levels, frequently normalizes close to or to pre-injury levels, suggesting the return of normal kidney function. However, animal studies have shown that there is ultrastructural damage from incomplete tubular repair and persistent inflammation and deposition of extracellular matrix, together resulting in functional defects such as a decrease in urinary concentrating ability as well as salt sensitivity [31]. These defects contribute to continuous tissue damage by hypoxia as a result of micro-vessel 
rarefication, ultimately resulting in slowly progressive interstitial fibrosis and loss of function. The notion that kidney function is not back to pre-injury baseline levels is backed by large epidemiological databases showing that AKI is a trigger for subsequent declining kidney function, with a large proportion of patients progressing to advanced-stage CKD and eventually end-stage renal disease (ESRD) [32]. Opponents of this hypothesis posit that the most vulnerable patients would have progressed to ESRD without a triggering episode of AKI, since the same risk factors that predispose to AKI are responsible for progression of CKD [32]. These risk factors include, but are not limited to, the metabolic syndrome, obesity, hypertension, diabetes, and cardiovascular diseases. By the same token, the very same risk factors also predispose to the development of AKI, which blurs the lines between causality and association [33]. Thus, it comes as no surprise that the patients with the lowest level of kidney function were the most likely to progress to ESRD [34].

An important component of CKD development after AKI is maladaptive repair carried out by fibroblasts, pericytes, and myofibroblasts, with resultant interstitial renal scar formation and progressive nephron loss [35]. Tubular epithelial cells contribute to this process by cell cycle arrest and subsequent production of transforming growth factor-beta, thereby further fueling the process of progressive fibrosis. However, the types of cells causing progressive fibrosis after AKI are still being debated. Obvious candidates include epithelial cells, resident fibroblasts, bone marrow cells, endothelial cells, and pericytes [36]. Several groups identified epithelial-mesenchymal transition as a major profibrotic mechanism in CKD. Accordingly, proximal tubular epithelial cells transform into fibroblast-like cells and thereby initiate and promote interstitial fibrosis. Lineage-tracing studies, however, have not been able to reproduce this finding and identified pericytes as the main contributors to the fibrotic cell populations [37]. Yet the definitive origin of myofibroblasts responsible for extracellular matrix deposition remains to be elucidated.

\section{Conclusions}

AKI remains a major contributor to morbidity and mortality in hospitalized patients, and effective interventions to reduce mortality are currently not available. The current research focus is on the epidemiology and cellular substrate of the chronic kidney damage resulting from an episode of AKI. Answers regarding the cells that are responsible for the progressive interstitial fibrosis after AKI have obvious therapeutic relevance. The pathophysiology of AKI is highly complex and involves multiple cellular systems, including the endothelium, tubular cells, and leukocytes. Given the complex pathophysiology of AKI and the various comorbidities of affected patients, effective interventions need to be directed at all major pathophysiological components of this serious complication. Given the multitude of pathophysiological components, it appears that targeting only one or a few of the principal pathomechanisms of AKI would likely be ineffective, as clinical trials in the past have shown.

\section{Abbreviations}

AKI, acute kidney injury; CKD, chronic kidney disease; ESRD, end-stage renal disease; NHS, National Health Service.

\section{Disclosures}

The authors declare that they have no disclosures.

\section{References}

I. Rewa O, Bagshaw SM: Acute kidney injury-epidemiology, outcomes and economics. Nat Rev Nephrol 2014, 10:193-207.

2. National Institute for Health and Care Excellence (NICE): Acute kidney injury: prevention, detection and management of acute kidney injury up to the point of renal replacement therapy; 2013, [http://www.nice.org.uk/guidance/cgl69/resources/ cgl69-acute-kidney-injury-costing-statement2]

3. Chertow GM, Burdick E, Honour M, Bonventre JV, Bates DW: Acute kidney injury, mortality, length of stay, and costs in hospitalized patients. J Am Soc Nephrol 2005, I 6:3365-70.

4. Zarjou A, Agarwal A: Sepsis and acute kidney injury. J Am Soc Nephrol 2011, 22:999-1006.

5. Gomez H, Ince C, Backer D de, Pickkers P, Payen D, Hotchkiss J, Kellum JA: A unified theory of sepsis-induced acute kidney injury: inflammation, microcirculatory dysfunction, bioenergetics, and the tubular cell adaptation to injury. Shock 20I4, 4I:3-II.

6. Singh AP, Junemann A, Muthuraman A, Jaggi AS, Singh N, Grover K, Dhawan R: Animal models of acute renal failure. Pharmacol Rep 2012, 64:31-44.

7. Sutton TA, Fisher CJ, Molitoris BA: Microvascular endothelial injury and dysfunction during ischemic acute renal failure. Kidney Int 2002, 62:1539-49.

\section{FlOOOPrime}

\section{RECOMMENDED}

8. Linkermann A, Green DR: Necroptosis. N Engl J Med 2014, 370:455-65.

9. Liu J, Krautzberger AM, Sui SH, Hofmann OM, Chen Y, Baetscher M, Grgic I, Kumar S, Humphreys B, Hide WA, McMahon AP: Cellspecific translational profiling in acute kidney injury. J Clin Invest 20|4, I 24: I 242-54.

\section{FlOOOPrime}

RECOMMENDED

I0. Price PM, Safirstein RL, Megyesi J: The cell cycle and acute kidney injury. Kidney Int 2009, 76:604-I3.

II. Kusaba T, Lalli M, Kramann R, Kobayashi A, Humphreys BD: Differentiated kidney epithelial cells repair injured proximal tubule. Proc Natl Acad Sci USA 2014, I I I:1527-32.

\section{FlOOOPrime}

RECOMMENDED

12. Jiang M, Liu K, Luo J, Dong Z: Autophagy is a renoprotective mechanism during in vitro hypoxia and in vivo ischemiareperfusion injury. Am J Pathol 2010, I 76: I I81-92. 
13. Bonventre JV: Kidney ischemic preconditioning. Curr Opin Nephrol Hypertens 2002, I I:43-8.

14. Bonventre JV: Limb ischemia protects against contrast-induced nephropathy. Circulation 2012, I26:384-7.

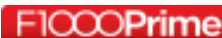
RECOMMENDED

15. Gobé G, Willgoss D, Hogg N, Schoch E, Endre Z: Cell survival or death in renal tubular epithelium after ischemia-reperfusion injury. Kidney Int 1999, 56:I299-304.

16. Heyman SN, Rosenberger C, Rosen S: Experimental ischemiareperfusion: biases and myths-the proximal vs. distal hypoxic tubular injury debate revisited. Kidney Int 2010, 77:9-16.

17. Liaño G, Pascual J: Acute renal failure. Madrid Acute Renal Failure Study Group. Lancet 1996, 347:479; author reply 479.

\section{FlOOOPrime}

\section{RECOMMENDED}

18. López-Gómez JM, Rivera F: Renal biopsy findings in acute renal failure in the cohort of patients in the Spanish Registry of Glomerulonephritis. Clin J Am Soc Nephrol 2008, 3:674-8I.

\section{FlOOOPrime}

\section{RECOMMENDED}

19. Kinsey GR, Okusa MD: Role of leukocytes in the pathogenesis of acute kidney injury. Crit Care 2012, 16:214.

20. Sutton TA, Hato T, Mai E, Yoshimoto $M$, Kuehl S, Anderson M, Mang $\mathrm{H}$, Plotkin Z, Chan RJ, Dagher PC: p53 is renoprotective after ischemic kidney injury by reducing inflammation. J Am Soc Nephrol 2013, 24: I 13-24.

\section{FlOOPrime}

\section{RECOMMENDED}

21. Dagher PC, Mai EM, Hato T, Lee S, Anderson MD, Karozos SC, Mang HE, Knipe NL, Plotkin Z, Sutton TA: The p53 inhibitor pifithrin- $\alpha$ can stimulate fibrosis in a rat model of ischemic acute kidney injury. Am J Physiol Renal Physiol 2012, 302:F284-91.

\section{FlOOOPrime}

22. Kusaba T, Humphreys BD: Controversies on the origin of proliferating epithelial cells after kidney injury. Pediatr Nephrol 2014, 29:673-9.

23. Vogetseder A, Palan T, Bacic D, Kaissling B, Le Hir M: Proximal tubular epithelial cells are generated by division of differentiated cells in the healthy kidney. Am J Physiol, Cell Physiol 2007, 292:C807-I3.

24. Fang T, Alison MR, Cook HT, Jeffery R, Wright NA, Poulsom R: Proliferation of bone marrow-derived cells contributes to regeneration after folic acid-induced acute tubular injury. J Am Soc Nephrol 2005, I6:1723-32.

25. Poulsom R, Forbes SJ, Hodivala-Dilke K, Ryan E, Wyles S, Navaratnarasah S, Jeffery R, Hunt T, Alison M, Cook T, Pusey C, Wright NA: Bone marrow contributes to renal parenchymal turnover and regeneration. J Pathol 200I, 195:229-35.
26. Humphreys BD, Valerius MT, Kobayashi A, Mugford JW, Soeung S, Duffield JS, McMahon AP, Bonventre JV: Intrinsic epithelial cells repair the kidney after injury. Cell Stem Cell 2008, 2:284-9I.

\section{FlOOOPrime}

\section{RECOMMENDED}

27. Lin F, Moran A, Igarashi P: Intrarenal cells, not bone marrowderived cells, are the major source for regeneration in postischemic kidney. J Clin Invest 2005, I I 5:|756-64.

\section{FlOOOPrime}

\section{RECOMMENDED}

28. Duffield JS, Bonventre JV: Kidney tubular epithelium is restored without replacement with bone marrow-derived cells during repair after ischemic injury. Kidney Int 2005, 68:|956-6I.

\section{FlOOOPrime \\ RECOMMENDED}

29. Romagnani P, Lasagni L, Remuzzi G: Renal progenitors: an evolutionary conserved strategy for kidney regeneration. Nat Rev Nephrol 2013, 9:137-46.

30. Berger K, Bangen J, Hammerich L, Liedtke C, Floege J, Smeets B, Moeller MJ: Origin of regenerating tubular cells after acute kidney injury. Proc Natl Acad Sci USA 2014, I I I:I533-8.

\section{FlOOOPrime}

\section{RECOMMENDED}

3I. Basile C: The long-term prognosis of acute kidney injury: acute renal failure as a cause of chronic kidney disease. J Nephrol 2008, 21:657-62.

32. Rifkin DE, Coca SG, Kalantar-Zadeh K: Does AKI truly lead to CKD? J Am Soc Nephrol 2012, 23:979-84.

\section{FECOMMENDED
RECOPRIme}

33. Chawla LS, Kimmel PL: Acute kidney injury and chronic kidney disease: an integrated clinical syndrome. Kidney Int 2012, 82:516-24.

34. Hsu C, Chertow GM, McCulloch CE, Fan D, Ordoñez JD, Go AS: Nonrecovery of kidney function and death after acute on chronic renal failure. Clin J Am Soc Nephrol 2009, 4:89I-8.

\section{FlOOOPrime}

\section{RECOMMENDED}

35. Yang L, Humphreys BD, Bonventre JV: Pathophysiology of acute kidney injury to chronic kidney disease: maladaptive repair. Contrib Nephrol 20I I, I 74: |49-55.

36. Kramann R, Dirocco DP, Maarouf OH, Humphreys BD: Matrix Producing Cells in Chronic Kidney Disease: Origin, Regulation, and Activation. Curr Pathobiol Rep 20I3, I.

37. Humphreys BD, Lin S, Kobayashi A, Hudson TE, Nowlin BT, Bonventre JV, Valerius MT, McMahon AP, Duffield JS: Fate tracing reveals the pericyte and not epithelial origin of myofibroblasts in kidney fibrosis. Am J Pathol 2010, 176:85-97. 